\title{
The population status of chameleons within Ranomafana National Park, Madagascar, and recommendations for future monitoring
}

\author{
Richard K. B. Jenkins, Lee D. Brady, Kieron Huston, Juliet L. D. Kauffmann, Jeanneney Rabearivony, \\ Georges Raveloson and J. Marcus Rowcliffe
}

\begin{abstract}
Malagasy chameleons are threatened by the relentless pace of habitat destruction. Their great popularity amongst herpetoculturalists has also resulted in collection for international animal markets. Most previous fieldwork has focused on the compilation of much needed species inventories, but little attention has been given to estimating chameleon population densities. This lack of information prevents a reliable assessment of the effects of habitat loss and direct exploitation on wild populations. A simple and repeatable methodology for the monitoring of chameleon populations is therefore urgently required. The present study developed survey techniques based
\end{abstract}

on distance sampling within an area of relatively undisturbed rain forest at Ranomafana National Park. In total 394 individuals from six species were recorded and population densities $( \pm \mathrm{SE})$ of $27.2 \pm$ 5.4/ha Brookesia spp. and $21.4 \pm 4.0 /$ ha Calumma spp. were estimated using the computer program DISTANCE. The authors propose that monitoring of chameleons in areas subject to different threats should begin immediately using the methods outlined in this paper.

Keywords Chameleon, Madagascar, population density, rain forest, trade.

\section{Introduction}

Although the degradation and destruction of forests are undoubtedly the primary threat to Madagascar's fauna (Raxworthy, 1988), the additional pressure of exploitation for international animal markets cannot be regarded as insignificant (IUCN/SSC Trade Specialist Group et al., 1993). Of all Madagascar's wildlife it is the herpetofauna that is perhaps the most threatened by such collection (Behra, 1993; IUCN/SSC Trade Specialist Group et al., 1993). Since the mid-1980s both the diversity and quantity of Malagasy reptiles in the trade have

Richard K. B. Jenkins School of Pure and Applied Biology, University of Wales, PO Box 915, Cardiff, CF1 3TL, UK.

Lee D. Brady (corresponding author), The Durrell Institute of Conservation and Ecology, University of Kent, Canterbury, Kent, CT2 7NJ, UK. E-mail: L.D.Brady@ukc.ac.uk

Kieron Huston Surrey Wildlife Trust, Pirbright, Surrey, UK.

Juliet L. D. Kauffmann Department of Biology, The Open University, Milton Keynes, UK.

Jeanneney Rabearivony and Georges Raveloson Universite d'Antananarivo, Madagascar.

J. Marcus Rowcliffe Institute of Zoology, Zoological Society of London, London, UK.

Received 31 October 1997. Accepted 24 July 1998 increased significantly and for some chameleon species increases of up to 400 per cent have been reported (World Conservation Monitoring Centre \& IUCN/SSC Trade Specialist Group, 1991; IUCN/SSC Trade Specialist Group et al., 1993). These figures probably underestimate the true number of individuals exported because mortality during transit is often undocumented (IUCN/ SSC Trade Specialist Group et al., 1993) and illegal exportation levels are difficult to quantify. Also, because chameleons require specialized husbandry (Bustard, 1989; de Vosjoli, 1990) captive breeding is unlikely to provide a sufficient supply of animals to meet increasing demands.

\section{The current trade}

In a review by the International Union for Conservation of Nature (IUCN) Trade Specialist Group, endemic Malagasy reptiles formed approximately 8 per cent of the species on Convention on International Trade in Endangered Species (CITES) Appendix II that were traded at levels likely to be a threat to wild populations (World Conservation Monitoring Centre \& IUCN/SSC Trade Specialist Group, 1991). The report concluded that by 1991 trade had increased for both CITES-listed and non-listed species to a level that may be detrimental to wild populations. Some of the species recorded in 
consignments to Europe, Japan and North America were considered too rare for collection, being often known to science from a single museum specimen (e.g. Furcifer belalandaensis Brygoo \& Domergue 1968 listed in IUCN/SSC Trade Specialist Group et al., 1993). Of most concern was the finding that all chameleon species recorded in the trade were poorly known in terms of population ecology, population density and other important biological parameters. For example, the impact of the trade in wild populations was 'unknown' for all 23 Brookesia species. Of the 34 Calumma and Furcifer (both formerly Chamaeleo and still referred to as such by CITES) species, the significance of trade was 'unknown, but believed to be insignificant' for 47 per cent of the species, while 41 per cent were too poorly known for an appraisal to be made (IUCN/SSC Trade Specialist Group et al., 1993). In 1995 the CITES Standing Committee recommended that from 1996 all CITIES Parties suspend imports of chameleons from Madagascar belonging to the genus Chamaeleo, with the exception of $C$. lateralis, C. oustaleti, C. pardalis and C. verrucosus (CITES Secretariat, 1995). Although these four species are widely distributed (Glaw \& Vences, 1994) and were not considered to be threatened by past levels of trade (IUCN/SSC Trade Specialist Group et al., 1993), no data on local population densities or the impact of collection on wild populations have ever been published.

\section{Sustainable harvesting of chameleons}

While trade in poorly known and rare species is a potential threat to their conservation, the abundance of some species may allow a level of collection that will not harm wild populations. It has been argued that sustainable harvesting has potential benefits for both rural communities and species conservation (e.g. Allen \& Edwards, 1995). Local collectors given a fair price for reptiles may value protected areas for the long-term revenue derived from collecting certain species at agreed quota levels. Increased trade in some widespread and common species may also compensate for the ban on trade in rarer species. How ever, for even the most common and widespread chameleons to be sustainably harvested, enough basic information on their ecology must exist to ensure a non-detrimental impact on the species at the local population level.

Previous chameleon studies in Madagascar have concentrated on the compilation of species inventories across a wide range of important sites (Raxworthy,
1988; Raxworthy \& Nussbaum, 1994) and have resulted in detailed information on geographical and altitudinal range (Raxworthy \& Nussbaum, 1995). While evidence highlighting the need for more extensive species inventories is provided by the continued descriptions of new chameleon species (e.g. Böhme, 1997), it is clear that before export quotas can be set at sustainable levels and directed at appropriate species, there needs to be more fieldwork to help define the range of chameleon population densities, followed by long-term monitoring at key sites. Although reptile search techniques have been developed and refined in recent years (Raxworthy, 1988; Raxworthy \& Nussbaum, 1994), there has been no attempt to publish even preliminary estimates of Malagasy chameleon population densities.

\section{Surveying for chameleons}

Distance sampling (fully described by Buckland et al., 1993) is becoming increasingly popular with biologists for estimating population densities (e.g. Heydon \& Bulloh, 1996). It provides an estimation of density by the calculation of a detection curve. This detection curve is based on a series of perpendicular distances measured from a transect line or point to the object of interest. The four main assumptions of this method are (after Buckland et al., 1993; Lancia et al., 1996):

1. transect lines or points are placed at random in relation to the objects' distribution;

2. all objects at zero distance from the transect line or point are detected;

3. objects are detected at their initial location, before any movement occurs as a result of disturbance from the observer;

4. perpendicular distances can be measured accurately.

Chameleons are most readily found at their nocturnal roost sites (Parcher, 1974; Raxworthy, 1988), where they become pale and immobile. Low-roosting individuals are therefore relatively easy to find using torch light (assumption 2) and do not move upon detection (assumption 3). Also, as long as roosting individuals are approached carefully, accurate measurements of perpendicular distances are possible (assumption 4).

The aim of the present study was to develop simple and repeatable line transect survey techniques based on distance sampling methodologies. Survey work was then undertaken in order to determine the population status of chameleons within an area of undisturbed rain forest at Ranomafana National Park. 


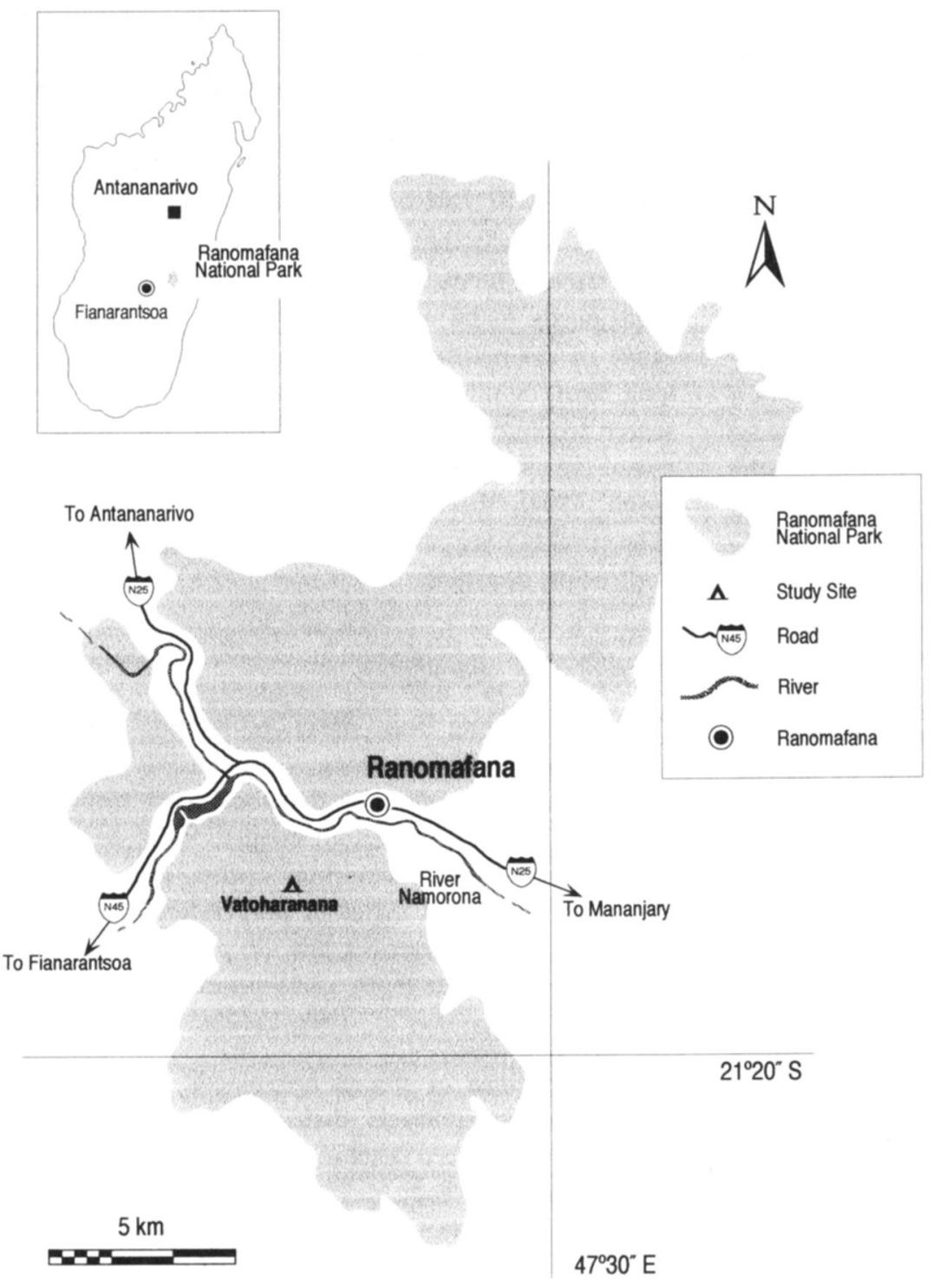

Fig. 1 Map illustrating location of study site within Ranomafana National Park.

\section{Materials and methods}

\section{Study area}

Ranomafana National Park $\left(21^{\circ} 17^{\prime} \mathrm{S}, 47^{\circ} 25^{\prime} \mathrm{E}\right.$; Fig. 1) is situated between 800 and $1200 \mathrm{~m}$ above sea level, with a mean daily temperature ranging from 3 to $35^{\circ} \mathrm{C}$. Rainfall is unevenly distributed over $c .200$ days, averaging $2600 \mathrm{~mm}$ per annum. The wettest months are January and February and the driest month is October (Razafimamonjy, 1988). The study site was Vatoharanana $(1030-1200 \mathrm{~m})$, an area of primary submontane cloud forest that was selectively logged more than 25 years ago (Kremen, 1992). The site is topographically diverse, consisting of steep-sided valleys and narrow ridge tops. The extensive forest trail system that exists within Ranomafana National Park is regularly used for the monitoring of several taxonomic groups as part of an ongoing biodiversity monitoring project (P. Wright, pers. comm.). Although herpetological surveys have been undertaken within the national park (e.g. Andreone, 1994) no published data exist for chameleons. At present direct chameleon exploitation is not known to occur.

\section{Survey methods}

The study was carried out over an 8-week period during the Malagasy summer (November 1993- 
Plate 1 Brookesia nasus, a highly cryptic, ground-dwelling chameleon that is abundant in undisturbed forest within Ranomafana National Park (L. D. Brady).

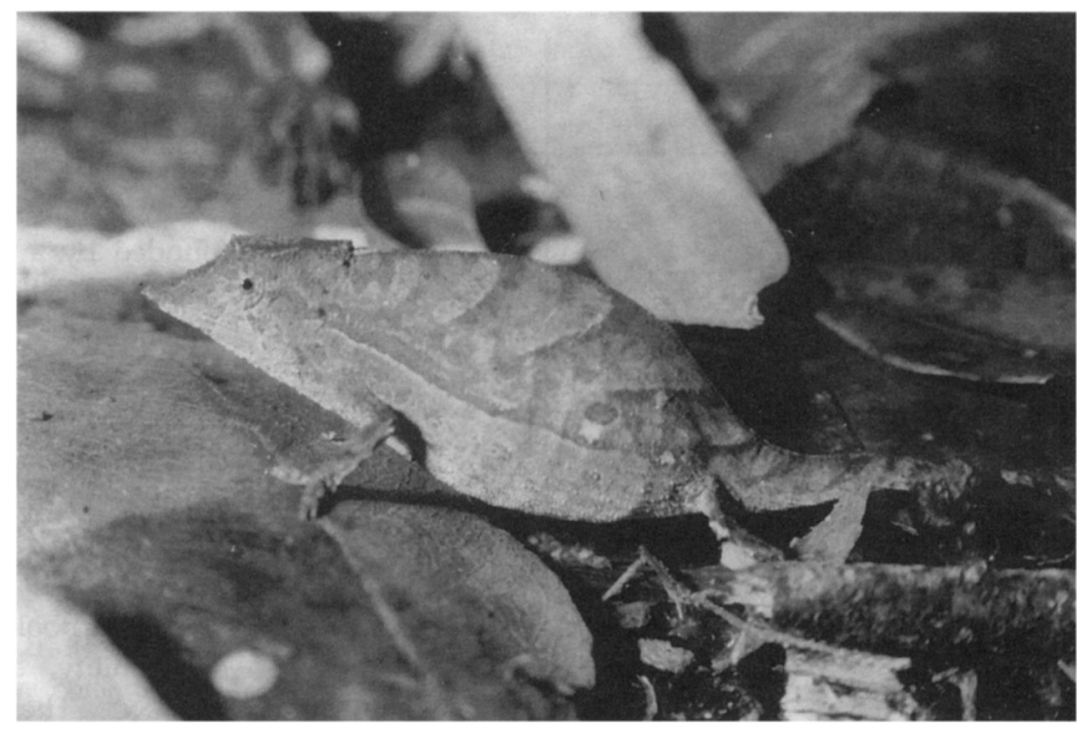

January 1994), timed to coincide with maximum chameleon activity (Raxworthy, 1988). Chameleon identifications were based on keys, illustrations and descriptive notes in Brygoo (1971, 1978) and Glaw \& Vences (1992). Animals were classified as hatchlings, juveniles and adults, and sexed according to size-class and morphology. These data were used to determine the population structure for each species.

Twenty randomly located forest line transects (total effort $3920 \mathrm{~m}$ ), each consisting of six parallel lines (mean line length $33 \mathrm{~m}$ with a $20-\mathrm{m}$ separation between adjacent lines; mean transect length $196 \mathrm{~m}$ ), were sampled. In order to limit the effects of disturbance on the distribution of chameleons within the transect area, all lines were set up at least $24 \mathrm{~h}$ before being surveyed. Although distance sampling data should be collected only along randomly located transects (see Introduction), the method was extended to surveys along sections of path to allow comparisons between the two habitat areas. Therefore, an additional 35 path line transects (total effort $6575 \mathrm{~m}$; mean transect length $188 \mathrm{~m}$ ) were sampled. Path transects ran directly along the trails with the baseline defined as the path edge (both sides). In order to prevent spiked data along path transects, chameleons found roosting directly above the trail were discounted from all density estimates.

Surveyors (working in teams of two) moved slowly (mean search speed $1.73 \mathrm{~m} / \mathrm{min}$ ) along each transect searching opposite flanks for roosting chameleons with the aid of 'Petzl Mega' head torches equipped with standard (i.e. non-halogen) bulbs. Searching for individuals roosting beneath low-lying vegetation often
Plate 2 The rarest chameleon at Vatoharanana was Brookesia thieli (J. M. Rowcliffe).

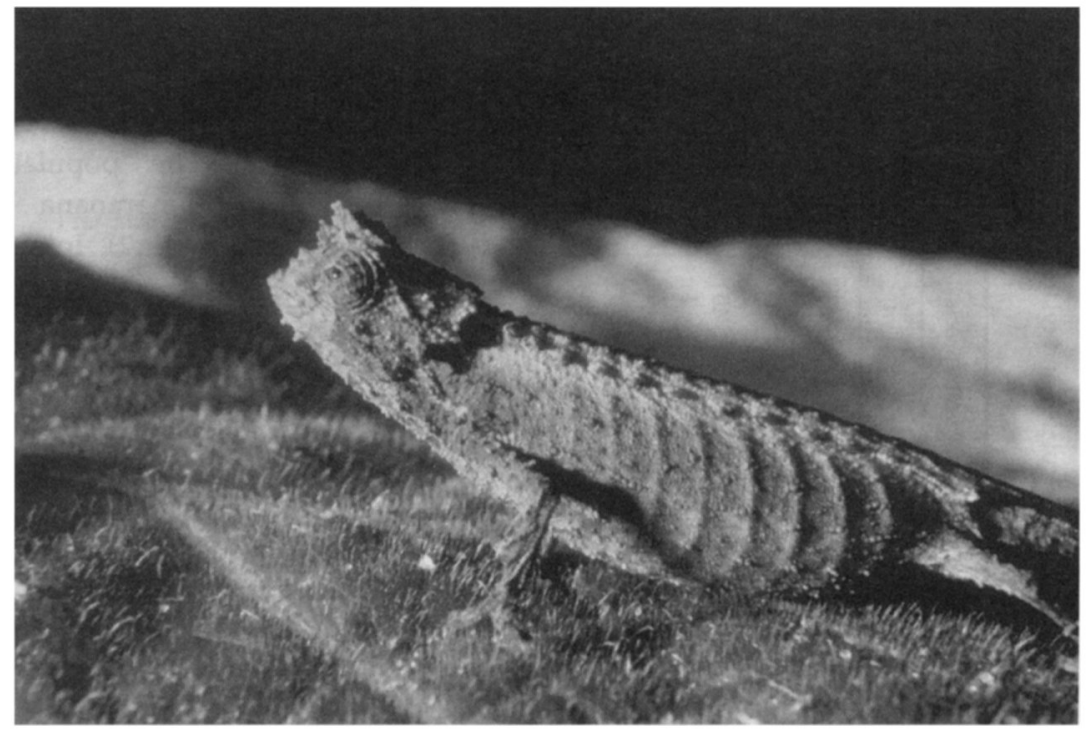




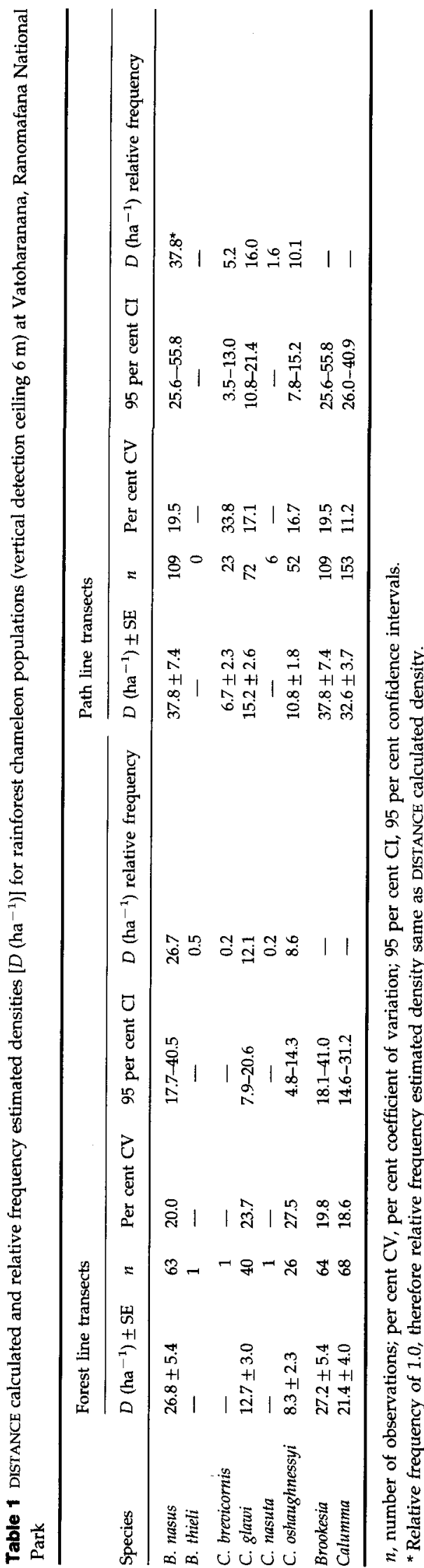

necessitated crawling on hands and knees. Variability in search effort between different observers was controlled by randomly assigning observers to each survey team.

Any ground-based census of arboreal animals is confounded by a decreasing vertical detection rate, so a 'detection ceiling' of $6 \mathrm{~m}$ was adopted for all density estimations. This ceiling was defined after examination of the roost height data and represented the vertical strata within which we were confident of observing all chameleons on the transect line.

The computer program DISTANCE (Laake et al., 1993) was used to estimate the densities of all species with more than 19 observations. Chameleon observations were also pooled into two groups based on perceived detectability, and group densities calculated using DISTANCE. These groups consisted of the small, lowroosting Brookesia spp. and the larger, more arboreal Calumma spp. Densities for species with few observations $(n<20)$ were estimated by multiplying the group density by the relative proportion of the group represented by each species.

\section{Results}

A total of 394 chameleons representing six species were detected along the line transects. The density of chameleons estimated for forest line transects was similar to the density estimated for path line transects (Table 1). However, most species, in particular B. nasus and C. brevicornis, displayed an increase in density on paths. In contrast $B$. thieli was not recorded from the trail system, being found only within the forest. Brookesia nasus (Plate 1) was the most abundant chameleon followed by C. glawi and C. oshaughnessyi. Calumma nasuta and $C$. brevicornis are known to occur within other areas of Ranomafana National Park (Brady et al., 1996) but were rarely encountered along forest line transects at Vatoharanana. The rarest species, with only a single observation, was $B$. thieli (Plate 2).

The population structure of Calumma spp. at Vatoharanana displayed a female-biased sex ratio (Table 2). Interestingly this trend was reversed for $B$. nasus. Although the majority of chameleons encountered were adult (Table 2), a significant proportion of observations consisted of juveniles. However, only a small number of hatchling chameleons were recorded. Unfortunately the results for $B$. thieli and C. nasuta are based upon too small a sample size to be meaningful.

\section{Discussion}

Population status

None of the 57 Malagasy chameleon species included in 
Table 2 Population structure of rain-forest chameleons found at Vatoharanana, Ranomafana National Park

\begin{tabular}{|c|c|c|c|c|c|c|c|}
\hline \multirow[b]{2}{*}{ Species } & \multicolumn{3}{|l|}{ Sex } & \multicolumn{4}{|c|}{ Life-stage } \\
\hline & $n$ & Male & Female & $n$ & Hatchling & Juvenile & Adult \\
\hline B. nasus & 170 & 0.54 & 0.46 & 176 & 0.00 & 0.17 & 0.83 \\
\hline B. thieli & 1 & - & - & 1 & 0.00 & 0.00 & 1.00 \\
\hline C. brevicornis & 18 & 0.28 & 0.72 & 24 & 0.00 & 0.12 & 0.88 \\
\hline C. glawi & 17 & 0.29 & 0.71 & 113 & 0.01 & 0.05 & 0.94 \\
\hline C. nasuta & 4 & 0.50 & 0.50 & 8 & 0.00 & 0.25 & 0.75 \\
\hline C. oshaughnessyi & 59 & 0.31 & 0.69 & 81 & 0.09 & 0.35 & 0.57 \\
\hline
\end{tabular}

Data represents proportions of total observations $(n)$ along combined forest and path line transects (vertical detection ceiling $6 \mathrm{~m}$ ).

$n$ does not always correspond to $n$ in Table 1 because (a) perpendicular distance data was truncated and (b) it was not possible to determine sex and life-stage for all individuals. a report on the impact of international trade was considered to be immediately threatened by collection for the pet trade (IUCN/SSC Trade Specialist Group et al., 1993). However, all of these species were too poorly known in terms of their distribution, abundance and ecology for a reliable assessment to be made. Although a partial ban on the import of Malagasy Chamaeleo spp. into countries that are Parties to CITES is in place (CITES Secretariat, 1995), it is by no means certain that it will continue indefinitely and the impact of the trade on the four permissible species (Calumma lateralis, C. oustaleti, $C$. pardalis and $C$. verrucosus) remains unclear. This study has shown that detailed information on local population density can be collected, even for some of the least-studied species (e.g. B. nasus and C. glawi). Table 3 shows the status of the six chameleon species found in this study. Brookesia nasus, C. oshaughnessyi, C. brevicornis and $C$. nasuta are widely distributed and are not under immediate threat from collection. However, if our estimates for B. thieli, C. brevicornis and C. nasuta are indicative of their density at other sites, then, despite their widespread distribution, local populations of these species are potentially at risk and more information from a wide range of habitats is clearly needed. Calumma glawi is a newly described species known only from Ranomafana National Park (Böhme, 1997) and is therefore also considered vulnerable.

The absence of direct chameleon exploitation from within Ranomafana National Park combined with the relatively undisturbed Vatoharanana forest provides an opportunity for future projects to monitor natural fluctuations in chameleon populations.

\section{Monitoring chameleon population densities}

Searching at night using head torches proved a reliable method of finding chameleons, with almost 400 observations. As noted by Parcher (1974), Calumma species

Table 3 The level of trade and the likely impact on wild populations for the species recorded at Vatoharanana, Ranomafana National Park (data from Brygoo, 1971, 1978; IUCN/SSC Trade Specialist Group et al., 1993; Glaw \& Vences, 1994; Böhme, 1997)

\begin{tabular}{|c|c|c|c|c|c|}
\hline \multirow[b]{2}{*}{ Species } & \multirow[b]{2}{*}{ Recorded distribution } & \multirow[b]{2}{*}{ Presence in trade } & \multirow[b]{2}{*}{ Effect of trade } & \multicolumn{2}{|c|}{$\begin{array}{l}\text { Status at } \\
\text { Vatoharananat }\end{array}$} \\
\hline & & & & Forest & Path \\
\hline B. nasus & Widespread (SE) & Unknown & Unknown & $* * * *$ & $* * * *$ \\
\hline B. thieli & Widespread, mid-altitude (E) & $\begin{array}{l}\text { Recorded but quantities un- } \\
\text { known }\end{array}$ & Unknown & * & - \\
\hline C. brevicornis & Widespread ( $\mathrm{N}$ and $\mathrm{E}$ ) & Common & $\begin{array}{l}\text { Unknown-not considered a } \\
\text { threat }\end{array}$ & * & $* *$ \\
\hline C. glawi & $\begin{array}{l}\text { Ranomafana National Park } \\
\text { only }\end{array}$ & $\begin{array}{l}\text { Unknown-species only recently } \\
\text { described }\end{array}$ & $\begin{array}{l}\text { Unknown-species only recently } \\
\text { described }\end{array}$ & $* * *$ & *** \\
\hline C. nasuta & Widespread ( $\mathrm{N}$ and $\mathrm{E}$ ) & Low & $\begin{array}{l}\text { Unknown-not considered a } \\
\text { threat }\end{array}$ & * & * \\
\hline C. oshaughnessyi & Widespread (NE, E and SE) & Low & $\begin{array}{l}\text { Unknown-not considered a } \\
\text { threat }\end{array}$ & $* *$ & $* * *$ \\
\hline
\end{tabular}

+ Based on density $\left(\mathrm{ha}^{-1}\right)$ data from line transects in current study: 一, not recorded; ${ }^{*}<5.0 ; * * 5.0-9.9 ; * * 10.0-19.9 ; * * * \geq 20.0$. 


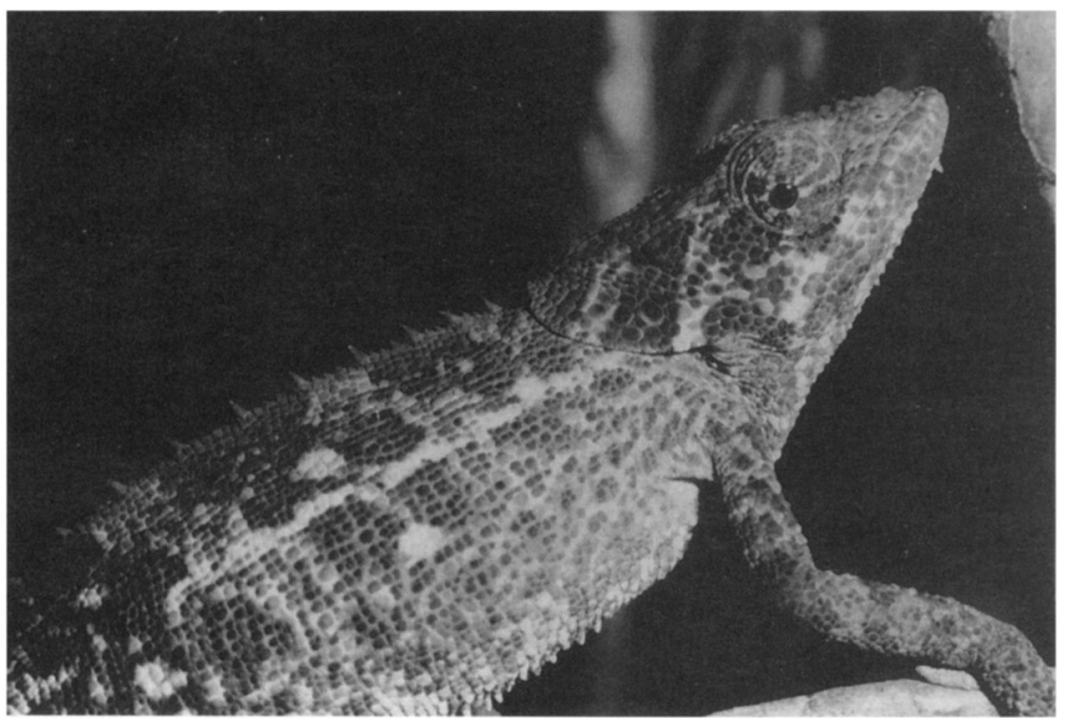

Plate 3 Some species of chameleon, such as this Calumma brevicornis, may favour the disturbed habitat characteristic of forest trails (L. D. Brady). tended to roost in prominent positions. They also became very pale at night and were therefore easily picked out by torch light. The observation by Raxworthy (1991) that Brookesia do not become pale at night was only partially supported in the present study. At night Brookesia did not become as pale as Calumma, but they did become paler than their day-time coloration and as a consequence were also relatively easy to find using torch light. The most difficult aspect of searching for Brookesia was crouching down and systematically checking beneath the leaves and stems of low-lying vegetation, while at the same time searching above to locate the more arboreal Calumma species. The search techniques used in this study assumed that all chameleons roosted in positions that permitted their nocturnal detection with torches. It is possible that other species may have been present but remained undetected as a result of their roosting behaviour. For example, it is unknown whether any of the species present roosted high in the canopy, out of vertical sight. Although future inventory-based surveys should consider accessing the forest canopy (e.g. O'Shea, 1992), we believe that ground-based surveys are currently the most practical method for monitoring chameleon populations, especially those at risk from collection.

One of the main advantages of distance sampling is that it allows some objects to remain undetected without compromising the precision of the density estimate. This is an important consideration when working in complex habitats such as rain forest. Controlling for the detectability of chameleons also enables conservation practitioners to compare densities across a wide range of both habitats and seasons. Densities calculated using distance sampling are based on the total distance surveyed and are independent of search time. Individual transect length is therefore highly flexible, allowing representative coverage of the area under investigation.

The magnitude of the caveats associated with line transects along trails effectively prohibits their recommendation for future monitoring projects. By their very nature, paths are non-randomly distributed, usually situated along ridges or by river margins and are not representative of the forest as a whole. Regularly used trails have a different habitat structure from the forest interior, typically possessing a denser layer of ground vegetation (Brady et al., 1996). This could have important ramifications for species such as Brookesia spp., which may be largely restricted to this ground layer (Glaw \& Vences, 1994). Trails are also subject to more rapid vegetation change than the forest interior. Monitoring of populations along trails may therefore reflect only changes in abundance and species composition in response to path disturbance. However, because many previous surveys have been restricted to areas alongside trails, the quantification of differences between populations within the forest interior and along paths is important. For example, Raxworthy \& Nussbaum (1994) searched mainly for reptiles close to the existing trails of Montagne d'Ambre National Park (Madagascar). Our results suggest that the density of rain-forest chameleons within the forest and along trails is different. Some species, such as $C$. brevicornis, may prefer the open and generally more disturbed habitat characteristic of trails, while other species may be completely absent (Plate 3 ).

Mark-recapture techniques have been recommended for assessing reptile population densities (Blomberg \& Shine, 1996). However, in the case of forest chameleons, this method has proved to have a number of shortcomings (Brady et al., 1996). First, very intensive effort is 
required, both to define the sampling area and to provide an adequate sample size, and the necessary manpower for this will rarely be available. Second, if systematic searching of an area is used to sample the population, the available analytical methods assume that random mixing of individuals takes place between samples (Krebs, 1989). Because chameleons are territorial, or at least have well defined home ranges (Kauffmann, 1994; Kauffmann et al., 1997), it is likely that the assumption of random mixing will be violated. This problem may be avoided by designing the search strategy to sample an area randomly, for example by using different observers to search a given area for subsequent sampling dates. However, it has not yet been shown that this can be done satisfactorily for chameleons, and such a requirement would add considerably to manpower costs.

Pitfall trapping is also a widely used technique (e.g. Gittens, 1987; Greenberg et al., 1994), but has proved to be unsuitable for chameleons, including the grounddwelling Brookesia spp. For example, during the Raxworthy \& Nussbaum (1994) study 2244 pitfall-days yielded only two individuals.

We therefore recommend that future monitoring programmes base their survey design on randomly located forest line transects. Distance sampling controls for detectability and is therefore well suited for the spatial and temporal comparison of chameleon population densities. However, to prevent density estimation errors caused by high-roosting individuals, especially above the transect line, field workers should consider applying a vertical detection ceiling to all observations.

\section{Conclusion}

The need for wide ranging species' inventories to clarify geographical distribution is justified both by the continued discovery of new species and the existence of species known only from the holotype or type locality. However, a review of reptile and amphibian species exported from Madagascar (IUCN/SSC Trade Specialist Group et al., 1993) recommended field research aimed at sustainable management for priority species and for information on the effects of collection on populations at different densities and different times of the year. Whilst this is clearly the long term goal, unless monitoring programmes are initiated now, both to collect baseline density data and investigate natural population fluctuations, it will become increasingly difficult to quantify the effect of collecting in the future. In view of the importance of Madagascar to global chameleon diversity and the lack of ecological knowledge on many species, detailed population studies on chameleons in areas subject to different threats should start immediately.

\section{Acknowledgements}

We would like to thank the Malagasy Government agencies (Eaux et Forêt and ANGAP), Ranomafana National Park Project and the Institute for the Conservation of Tropical Environments for permission to undertake research and logistical support. This project was supported by financial contributions from the University of East Anglia, Adrian Ashby-Smith Memorial Trust, Albert Reckitt Charitable Trust, British Ecological Society, Edinburgh Trust, Gilchrist Educational Trust, Institute of Biology, People's Trust for Endangered Species, Royal Geographical Society and the Sir Philip Reckitt Educational Trust.

\section{References}

Allen, C.M. \& Edwards, S.R. (1995) The sustainable-use debate: observations from IUCN. Oryx, 29, 92-98.

Andreone, F. (1994) The amphibians of Ranomafana rain forest, Madagascar-preliminary community analysis and conservation considerations. Oryx, 28, 207-214.

Behra, O. (1993) The export of reptiles and amphibians from Madagascar. TRAFFIC Bulletin, 13, 115-116.

Blomberg, S. \& Shine, R. (1996) Reptiles. In Ecological Census Techniques. A Handbook (ed. W.J. Sutherland), pp. 218226. Cambridge University Press, Cambridge.

Böhme, W. (1997) Eine neue Chamäleonart aus der Calumma gastrotaenia-Verwandtschaft Ost-Madagaskars. Herpetofauna, 19, 5-10 [in German].

Brady, L.D., Huston, K., Jenkins, R.K.B., Kauffmann, J.L.D., Rabearivony, J., Raveloson, G. \& Rowcliffe, M. (1996) UEA Madagascar Expedition '93. Final Report. Unpublished Report, University of East Anglia, Norwich.

Brygoo, E.R. (1971) Reptiles Sauriens Chamaeleonidae. Genre Chamaeleo. Faune de Madagascar, 33, 1-318 [in French].

Brygoo, E.R. (1978) Reptiles Sauriens Chamaeleonidae. Genre Brookesia et complément pour le genre Chamaeleo. Faune de Madagascar, 47, 1-173 [in French].

Buckland, S.T., Anderson, D.R., Burnham, K.P. \& Laake, J.L. (1993) Distance Sampling. Chapman and Hall, London.

Bustard, R. (1989) Keeping and breeding oviparous chameleons. British Herpetological Society Bulletin, 27, 1833.

CITES Secretariat (1995) Significant Trade in Animal Species included in Appendix II. Recommendations of the Standing Committee. Notification to the Parties No. 833, Convention on International Trade in Endangered Species of Wild Fauna and Flora, Gland.

Gittens, S.P. (1987) The diet of the common toad (Bufo bufo) around a pond in Mid-Wales. Amphibia-Reptilia, 8, 13-17.

Glaw, F. \& Vences, M. (1992) A Fieldguide to the Amphibians and Reptiles of Madagascar, 1st edn. M. Vences and F. Glaw, Cologne.

Glaw, F. \& Vences, M. (1994) A Fieldguide to the Amphibians 
and Reptiles of Madagascar, 2nd edn. M. Vences and F. Glaw, Cologne.

Greenberg, C.H., Neary, D.G. \& Harris, L.D. (1994) A comparison of herpetofaunal sampling effectiveness of pitfall, single-ended, and double-ended funnel traps used with drift fences. Journal of Herpetology, 28, 319-324.

Heydon, M. J. \& Bulloh, P. (1996) The impact of selective logging on sympatric civet species in Borneo. Oryx, 30, $31-36$.

IUCN/SSC (Species Survival Commission of the World Conservation Union) Trade Specialist Group, BIODEV, IUCN/ SSC Madagascar Reptile and Amphibian Specialist Group (1993) A Preliminary Review of the Distribution and Status of Reptile and Amphibian Species exported from Madagascar. Joint Nature Conservation Committee Report, Peterborough.

Kauffmann, J. (1994) Veldwaarnemingen aan Calumma brevicornis en $\mathrm{C}$. oshaughnessyi ambreensis op Madagascar. Lacerta, 53, 2-10 [in Dutch].

Kauffmann, J.L.D., Brady, L.D. \& Jenkins, R.K.B. (1997) Behavioural observations of the chameleon Calumma oshaughnessyi in Madagascar. Herpetological Journal, 7, 77-80.

Krebs, C.J. (1989) Ecological Methodology. Harper Collins, New York.

Kremen, C. (1992) Assessing the indicator properties of species assemblages for natural areas monitoring. Ecological Applications, 2, 203-217.

Laake, J.L., Buckland, S.T., Anderson, D.R. \& Burnham, K.P. (1993) DISTANCE User's Guide. Version 2.0. Colorado Cooperative Fish and Wildlife Research Unit, Colorado State University, Fort Collins.

Lancia, R.A., Nichols, J.D. \& Pollock, K.H. (1996) Estimating the number of animals in wildlife populations. In Research and Management Techniques for Wildlife and Habitat, 5th edn (ed. T. A. Bookout), pp. 215-253. The Wildlife Society, Bethesda, MD.

O'Shea, M. (1992) Expedition Field Techniques. Reptiles and Amphibians. Expedition Advisory Centre, London.

Parcher, S.P. (1974) Observation on the natural histories of six Malagasy Chamaeleontidae. Zeitschrift Tierpsychol, 34, 500523.

Raxworthy, C.J. (1988) Reptiles, rainforests and conservation in Madagascar. Biological Conservation, 43, 181-211.
Raxworthy, C.J. (1991) Field observations on some dwarf chameleons (Brookesia spp.) from rainforest areas of Madagascar. Journal of Zoology, London, 224, 11-25.

Raxworthy, C.J. \& Nussbaum, R.A. (1994) A rainforest survey of amphibians, reptiles and small mammals at Montagne d'Ambre National Park, Madagascar. Biological Conservation, 69, 65-73.

Raxworthy, C.J. \& Nussbaum, R.A. (1995) Systematics, speciation and biogeography of the dwarf chameleons (Brookesia; Reptilia, Squamata, Chamaeleontidae) of northern Madagascar. Journal of Zoology, London, 235, 525-528.

Razafimamonjy, D. (1988) Etude d'un écosystème forestier de Ranomafana. In L'Equilibre des Écosystèmes Forestiers á Madagascar. Actes d'un Séminaire International (L. Rakotovao, V. Barre and J. Sayer), pp. 315-319. IUCN, Gland and Cambridge.

de Vosjoli, P. (1990) The General Care and Maintenance of True Chameleons. Part I Husbandry. The Herpetological Library, Lakeside.

World Conservation Monitoring Centre and IUCN/SSC Trade Specialist Group (1991) Review of Significant Trade in Animals included in Appendix II of CITES. Draft Report submitted to the CITES Animal Committee. World Conservation Monitoring Centre and IUCN/SSC Trade Specialist Group, August 1991.

\section{Biosketches}

Lee Brady's principal area of research is species ecology, with particular reference to herpetology. Recent projects have investigated the effects of aquatic pollutants on amphibians and the adaptive development strategies displayed by tadpoles in a variable environment. Current research focuses upon the ecology of Malagasy chameleons. By training Malagasy students in methods of biodiversity assessment this work aims to determine the impact of habitat disturbance on chameleon populations and prepare a management plan for their conservation that will also benefit local communities 